\title{
TRABALHADOR RURAL, SIM, "SINHÔ": ESTUDO DE CASO NO ÂMBITO DE UMA VARA FEDERAL DO MARANHÃO
}

\section{RURAL WORKER, PROUDLY: CASE STUDY WITHIN THE AMBIT OF THE FEDERAL COURT OF MARANHÃO}

Resumo: A presente pesquisa dissertou sobre o tema Justiça Cidadã, desdobrandose no eixo Democratização da Justiça. Propôs-se o estudo de caso acerca de uma ação judicial ajuizada em uma Vara Federal do Maranhão. Essa análise caracterizou uma estratégia pedagógica suscitada para propiciar o ensino sobre o auxílio-doença previdenciário, na disciplina de Prática Previdenciária. Aplicou-se a teoria cognitiva de Vygotsky, que focaliza na linguagem para estimular o processo de ensinoaprendizagem. Coadunou-se um diálogo acadêmico (Universidade) e institucional (Justiça Federal) a fim de desvendar a importância da democratização da Justiça, no panorama da Justiça Cidadã. Apreciou-se o auxílio-doença previdenciário por ser, na contemporaneidade, o assunto mais demandado no âmbito dos Juizados Especiais Federais. Visou investigar o ensino por meio de um problema; articular a reflexão sobre uma experiência; e constatar o ensino com a pesquisa. É um estudo exploratório, com aspecto qualitativo; compreendeu os procedimentos bibliográfico e documental, além da utilização do estudo de caso. Percebeu-se que o estudo de caso é preceituado pelas diretrizes pedagógicas para Formação e Aperfeiçoamento de Magistrados da Escola Nacional de Formação e Aperfeiçoamento de Magistrados (ENFAM) e pelo Projeto Político Pedagógico da Escola da Magistratura Regional Federal da $2^{a}$ Região (EMARF). Notou-se que, nesse ensaio, o estudo de caso constituiu uma metodologia adequada para desenvolver as lições referentes ao auxílio-doença, na Prática Educativa da Prática Previdenciária. Teve-se, ao final, que o estudo de caso trabalhou a autonomia cognitiva na construção do saber com ênfase na independência no processo de ensino-aprendizagem, à luz da concepção teórica de Vygotsky.

Palavras-chave: Justiça Federal. Juizados Especiais Federais. Auxílio-doença previdenciário. Vara Federal do Maranhão. Prática Previdenciária.

Abstract: This research was related to Citizen Justice, pointing to the Democratization of Justice axis. Proposed a case study on a lawsuit filed in a Federal Court of Maranhão. Such analysis characterized a pedagogical strategy raised for teaching about social security sickness aid, in the discipline of Social Security Practice. For this, the Vygotsky's cognitive theory was applied, which focuses on language to stimulate the teaching-learning process. An academic (University) and institutional (Federal Justice) dialogue was adopted to uncover the importance of the

\footnotetext{
* Especialista em Gestão Pública pela Universidade Federal do Maranhão (UFMA). Pós Graduada em Advocacia Trabalhista pela Universidade Anhanguera. Graduanda em Licenciatura em Pedagogia pela Universidade Estadual do Maranhão (UEMA). E-mail: const_erica@hotmail.com.
} 
democratization of Justice, within the ambit of the Citizen Justice. Social security sickness aid was appreciated because it is currently the most demanded subject within the scope of the Federal Special Courts. It intended to investigate teaching through a problem; support a reflection on an experience; and verify teaching with research. It was an exploratory study, with a qualitative aspect; which used the bibliographic and documentary procedures, in addition to the use of the case study. It was noticed that the case study is prescribed by the pedagogical guidelines for Training and Improvement of Magistrates of the National School of Training and Improvement of Magistrates (ENFAM) and by the Political Pedagogical Project of the Federal Regional School of Magistrates of the 2nd Region (EMARF). It was also perceived that he case study consisted of the adequate methodology to develop the lessons related to sickness aid, in the Educational Practice of Social Security Practice. In the end, the case study worked the cognitive autonomy in the construction of knowledge, emphasizing the independence in the teaching-learning process, in the light of Vygotsky's theoretical conception.

Keywords: Federal Justice. Federal Special Courts. Social Security Sickness Aid. Federal Court of Maranhão. Social Security Practice. 


\section{INTRODUÇÃO}

Esse trabalho abarca uma Justiça Cidadã, que ilustra os conceitos de democratização da Justiça.

Explora o estudo de caso - relativo a uma demanda processual protocolada em uma Vara Federal do Maranhão -, como metodologia de ensino para esmiuçar o auxílio-doença previdenciário. Fundamenta-se na teoria pedagógica de Vygotsky, que aponta a linguagem como elemento essencial para propiciar a aquisição de conhecimento.

Assim, na perspectiva literária, sugestiona uma interface acadêmica e institucional, a instigar a reflexão sobre a importância da democratização da Justiça.

Consiste em uma análise que relaciona Direito Constitucional e Direito Previdenciário. Isso se deve porque o caso inspecionado ventila sobre o benefício de auxílio-doença previdenciário.

O caso perquirido é uma demanda processual postulada em um Juizado Especial Federal, anexo a uma Vara Federal do Maranhão. Cinge-se a questão no tocante a um vulnerável: trabalhador rural, com idade avançada e incapacidade laboral reconhecida no âmbito administrativo do Instituto Nacional do Seguro Social em período superior a cinco anos. Insta, assim, a debater sobre os princípios de justiça. Por consequência, esse estudo deságua em alcance social.

Essa pesquisa teve o seguinte problema: qual metodologia é adequada para estimular acadêmicos de Direito, da disciplina Prática Previdenciária, à aprendizagem sobre o auxílio-doença?

Objetivou desenvolver, por meio do estudo de caso, uma proposta de ensino coerente para lecionar sobre o auxílio-doença no panorama da Prática Previdenciária. Nesse caminho, buscou legitimar a aprendizagem por meio de um problema; mediar a reflexão sobre uma experiência; e permear o ensino com a pesquisa.

O artigo está estruturado nas partes, em síntese, indicadas neste parágrafo. Explanará o percurso metodológico obedecido para concretizar os objetivos da pesquisa. Discorrerá acerca do referencial teórico que ancorou a linha de pesquisa investigada. Apresentará a análise do estudo de caso, demarcando os pontos 
fundamentais do objeto de estudo detalhado. Por fim, exporá as conclusões obtidas a partir da respectiva apreciação dos dados.

O presente trabalho é relevante em razão da pertinência temporal do tema versado. Isso acontece porque focaliza no auxílio-doença previdenciário - o maior assunto demandado na Justiça Federal brasileira na atual conjuntura, no âmbito dos Juizados Especiais Federais. Em sendo assim, é evidente a repercussão social desse estudo.

Demais disso, ao suscitar/despertar o entendimento do conteúdo por meio do estudo de caso em uma contextualização científica, tendeu em aguçar a curiosidade do leitor e promover a eficiência didática. Dessa forma, resta claro o impacto científico dessa pesquisa.

Em suma, essa investigação explora uma Prática Educativa, no viés da Prática Previdenciária. Aventa a metodologia ativa do estudo de caso como estratégia pedagógica - permeada pela teoria cognitiva de Vygotsky -, a colaborar com o ensino do auxílio-doença. Portanto, nota-se a importância acadêmica desse escrito.

\section{PROCEDIMENTOS METODOLÓGICOS}

O estudo em pauta relaciona uma Justiça Cidadã, deslindando no eixo da democratização da Justiça.

Instiga o ensino sobre o auxílio-doença previdenciário por meio do estudo de caso sobre um litígio proposto em uma Vara Federal do Maranhão, sob o aspecto da teoria pedagógica de Vygotsky - que frisa na linguagem para fomentar a assimilação de saberes.

Desse ponto, estabelece, na abordagem teórica, uma interface acadêmica e institucional entre a Universidade e a Justiça Federal para ponderar sobre a democratização da Justiça.

Realça-se que esse estudo crítico do direito englobou caso que envolve vulnerável, unindo conhecimento técnico com os ensinamentos de formação humanística. 
É uma pesquisa do tipo exploratória, uma vez que "[...] tem como finalidade proporcionar mais informações sobre o assunto [...]." (PRODANOV; FREITAS, 2013, p. 51).

A pesquisa teve abordagem qualitativa, pois não focalizou a utilização de ferramenta estatística e para a obtenção do resultado não foram aplicadas técnicas de medição ou listada classificação. (FRASSON; OLIVEIRA JÚNIOR, 2010).

De igual modo, guiou-se pelo procedimento bibliográfico ao embasar-se em fontes escritas, bem como pelo documental, por pesquisar o documento nomeado Justiça em Números, quanto ao resultado do ano-base 2018. Este, por sua vez, foi elaborado pelo Conselho Nacional de Justiça e publicado em 2019 na categoria de pesquisa judiciária, no portal da referida instituição pública.

E, ainda, aplicou o estudo de caso, eis que trata da apreciação de um objeto para obtenção de um saber que coadune os aspectos: geral e específico. (SOUSA; SERRA, 2011). Nessa linha de ideias, Fachin (2006) sublinha que "[...] no método do estudo de caso, leva-se em consideração, principalmente, a compreensão, como um todo, do assunto investigado." (FACHIN, 2006, p. 45).

Ademais, "[...] um estudo é uma descrição analítica de um evento ou de uma situação in loco. Se bem apreciado, atinge a expressão máxima, sendo de grande valia." (FACHIN, 2006, p. 47).

Explanou-se, nesses termos, a trajetória metodológica que conduziu essa pesquisa.

\section{CONCEPÇÕES INICIAIS}

Esse artigo aborda a Justiça Federal, tida como uma Justiça Cidadã, uma vez que dialoga com as lições de democratização da Justiça.

Aponta o estudo de caso de uma lide instaurada em uma Vara Federal do Maranhão como estratégia pedagógica para conceber a compreensão sobre o auxíliodoença previdenciário, em consonância com a ótica de Vygotsky - que enfatiza as concepções linguísticas para aguçar a aprendizagem.

Ao descortinar tal campo investigativo, foi possível perceber que atualmente "os desafios relacionados à educação estão em todas as áreas do saber. No caso do 
ensino jurídico, há uma crise constante das mais diversas ordens, o que inclui métodos de repassar o conhecimento em sala de aula." (CINTRA; CAMURÇA; REIS, 2017, p. 408).

Notando essa inquietude, a presente apreciação deslinda sobre o estudo de caso por observar os preceitos contidos na Resolução n 7, de 7 de dezembro de 2017, que dispõe sobre as diretrizes pedagógicas para Formação e Aperfeiçoamento de Magistrados da Escola Nacional de Formação e Aperfeiçoamento de Magistrados (ENFAM). Então, cabe explicitar que:

[...] a prática pedagógica deve promover espaços de intercâmbio de experiências, mediante a proposição de estratégias que viabilizem 0 compartilhamento de aprendizagens, tais como: trabalhos em grupo, world cafés, painéis integrados, fóruns de discussão, estudos de caso e outras que podem ser utilizadas pelo docente para atingir os objetivos propostos. (ESCOLA NACIONAL DE FORMAÇÃO E APERFEIÇOAMENTO DE MAGISTRADOS, 2017, p. 24, grifo nosso).

Seguindo essa linha de raciocínio, convém destacar a percepção da Escola da Magistratura Regional Federal da $2^{a}$ Região (EMARF), exposta no Projeto Político Pedagógico, estabelecido pela Portaria EMARF NO TRF2-PTE-2016/00005 de 4 de novembro de 2016. Dessa forma, estabelece que:

[...] as técnicas que utilizam a experiência dos adultos aprendizes - como discussões em grupo, exercícios de simulação, atividades de resolução de problemas, estudos de caso e métodos de laboratório - serão mais eficazes que as técnicas de transmissão. (ESCOLA DA MAGISTRATURA REGIONAL FEDERAL DA 2a REGIÃO, 2016, p. 21, grifo nosso).

Por conseguinte, distingue-se o estudo de caso como uma estratégia pedagógica bem-conceituada pelos posicionamentos adotados pela ENFAM e pela EMARF - 2a Região.

A partir dessas pontuações, pertine identificar o teórico que sinalizou em sua formulação o ensino mediado por metodologias ativas. Dentro dessa roda de discussão, articula-se que:

Quando trabalhamos com metodologias ativas [...] e que tem suas raízes na visão de Vygotsky, de que existe uma natureza social inerente ao processo de aprendizagem [...] a construção do conhecimento permite o desenvolvimento de importantes competências [...]. (BRASIL, 2020, grifo nosso).

Ademais, 
o educador se torna mediador e procura instigar o aprendiz à pesquisa e ao desenvolvimento de uma visão crítica, por meio de formulação de problemas e hipóteses. Nesse processo, cabe ao estudante ser protagonista da sua aprendizagem. (BRASIL, 2020, grifo nosso).

Assim, vale explorar a teoria cognitiva/concepção teórica lecionada por Vygotsky ao vislumbrar a sua aplicação no caso em tela. Salienta-se que Lakomy (2014) defende que "Vygotsky destaca as contribuições da cultura, da interação social e da linguagem para o processo de desenvolvimento e aprendizagem social e histórica do sujeito." (LAKOMY, 2014, p. 34, grifo nosso).

Igualmente, Nogueira e Leal (2015) consideram que:

Podemos compreender, então, que é necessário um método que revele o que o sujeito pensa, o que representa e o que compreende das suas relações com o mundo. Assim, diante da fala do sujeito, acreditamos encontrar essa representação ou compreensão do pensamento. Afinal, precisamos levar o sujeito a exteriorizar o seu pensamento, sendo que somente na palavra falada é que será possível captar o momento de verdade, ou seja, buscar a gênese social do indivíduo, para compreender o que 0 constitui social, emocional e pessoalmente. (NOGUEIRA; LEAL, 2015, p. 154, grifo nosso).

Desse modo, assinalaram-se as concepções iniciais que alicerçam a linha de investigação dissertada nesse artigo.

\section{FUNDAMENTAÇÃO TEÓRICA ACERCA DO AUXÍlIO-DOENÇA PREVIDENCIÁRIO}

Sabe-se que a Constituição Federal de 1988, em seu artigo 194, preceitua que:

Art. 194. A seguridade social compreende um conjunto integrado de ações de iniciativa dos poderes públicos e da sociedade, destinadas a assegurar os direitos relativos à saúde, à previdência e à assistência social. (BRASIL, [1988]).

Com base nisso, ao estudar esse campo de estudo, tem-se que a seguridade social no Brasil inclui: a saúde, a previdência e a assistência social. Ao delinear esse percurso, nota-se que a Previdência Social é um direito social, determinado pela Constituição Federal de 1988. Veja-se:

Art. $6^{\circ}$ São direitos sociais a educação, a saúde, a alimentação, o trabalho, a moradia, o transporte, o lazer, a segurança, a previdência social, a 
proteção à maternidade e à infância, a assistência aos desamparados, na forma desta Constituição. (BRASIL, [1988], grifo nosso).

Fazendo a delimitação desse assunto, pertine abordá-lo no seguinte enfoque: modalidade de segurado - segurado especial. Tem-se que referido segurado consiste fundamentalmente: no trabalhador rural que exerce atividades agropecuárias individualmente ou no regime de economia familiar em pequena propriedade, sem empregados; ou no pescador artesanal.

Balizando-se esse conteúdo, considera-se consentâneo tratar do seguinte benefício em espécie: auxílio-doença previdenciário. Isso ocorre porque tal benefício constitui hodiernamente a demanda mais recorrente da Justiça Federal no âmbito dos Juizados Especiais Federais, conforme noticiado pelo Conselho Nacional de Justiça, no documento intitulado Justiça em Números, de 2019 - que englobou até o exercício 2018. (CONSELHO NACIONAL DE JUSTIÇA, 2019). Veja-se:

Figura 1 - Assuntos mais demandados.

Figura 182: Assuntos mais demandados nas turmas recursais

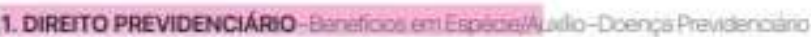

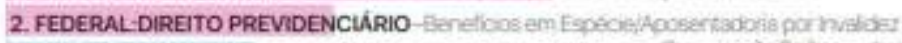

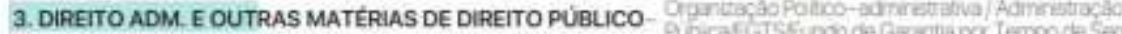

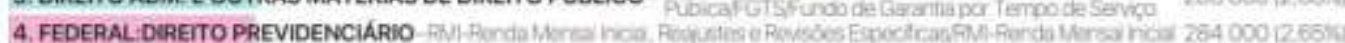

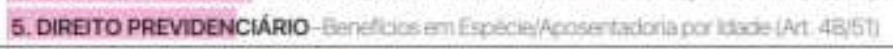

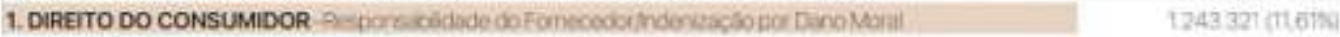

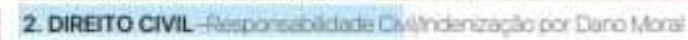

3. DIREITO CIVIL-Dbigactesfenpicies de Contratios:

4. DIREITO DO CONSUMIDOR - Oonureios de Connumafiancinon

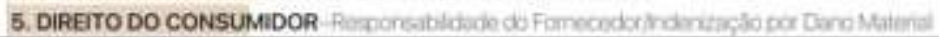

Figura 183: Assuntos mais demandados nos juizados especiais

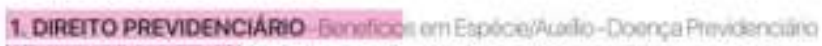

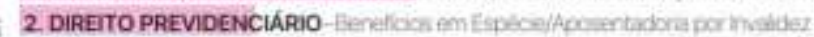

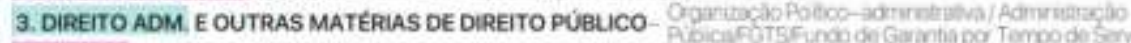

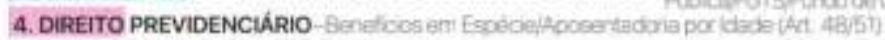

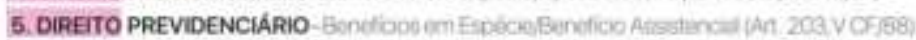

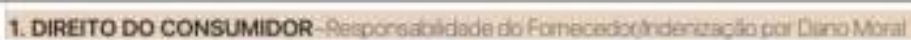

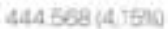

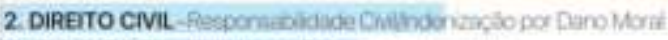

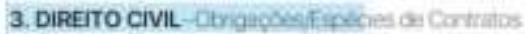

4. DIREITO CIVIL-Cbigagbesifispecies ae Tituics de Oredio

5. DIRETO DO CONSUMIDOR-Resconsablidede do Fornecedor/holenczacto por Deno Material

Fonte: Conselho Nacional de Justiça (2019).

Nesse cenário, Lazzari (2016) argumenta que: 
Os juizados especiais foram instituídos a partir de valores novos, voltados à modernização da prestação jurisdicional no Brasil, primando pela celeridade e eficiência nas soluções dos conflitos, atendendo ao desejo da população de acesso à Justiça de forma simples e com custos reduzidos. (LAZZARI, 2016, p. 33).

Insta asseverar que o segurado especial poderá fazer jus ao benefício em debate, quando estiver temporariamente incapacitado para o exercício das atividades laborais, desde que esse impedimento supere o período de quinze dias consecutivos. (BRASIL, 1991).

Por conseguinte, apresentou-se o embasamento literário que sustenta a linha de ideias articulada nessa pesquisa.

\section{ESTUdO dE CASO E SEUS REFLEXOS PEDAGÓgICOS}

Nesse horizonte, assinala-se que o estudo de caso objeto da investigação diz respeito a um lavrador que vive em um lugar por nome Pau Darco, localizado no interior do Maranhão.

Revela-se o planejamento elaborado com o intuito de obter resolução para a pergunta de partida desse estudo, bem como de cumprir os objetivos da pesquisa. Em tal vertente, a Tabela 1 declina especificamente os momentos planejados para estimular a aprendizagem sobre o auxílio-doença previdenciário de estudantes de Direito, na disciplina de Prática Previdenciária. Note-se:

Tabela 1 - Momentos Planejados da Aula de Prática Previdenciária Aventada.

\section{MOMENTOS PLANEJADOS - PRÁTICA PREVIDENCIÁRIA}

Elucidar os objetivos da aula e explicar as etapas.

Entregar em folha A4 o caso redigido.

Expor com a leitura verbal o relato do caso destacando as pontuações relevantes (pontos-chave, pontos básicos de ancoragem, subsunções da aprendizagem) contidas em slides.

Mediar a organização de equipes.

Atuar como mediador(a) do processo de ensino-aprendizagem ao dialogar o problema levantado: intercedendo por uma intervenção positiva na realidade estudada/investigada, a ser desenvolvida pelas equipes mediante apresentação de argumentos; intervindo na discussão para otimizar a reflexão sobre a experiência proposta; interferindo no debate para potencializar a percepção 
científica; e intermediando, ao final, a composição do conflito no sentido de reverberar um saber elaborado.

- Aplicação da concepção teórica de Vygotsky relativa à influência da linguagem no processo de ensino mediado pela comunicação dialógica na qual o(a) professor(a) assume o papel de mediador(a) da aprendizagem.

Fonte: Autor (2020).

A colocação encimada definiu o percurso para estudar os pontos de relevo atinentes ao auxílio-doença previdenciário, no contexto da Prática Previdenciária, mediante o estudo de caso sugestionado, à vista da teoria pedagógica de Vygotsky, na temática de orientação: Direito e Educação.

Nesse sentido, propôs-se, nessa reflexão teórica, um intercâmbio acadêmico e institucional que permeia a democratização da Justiça. Por isso, ressalta-se a visão de Cintra, Camurça e Reis (2017), uma vez que elucida que:

Assim, a chamada sociedade do conhecimento segue mudando o perfil das salas de aula repletas de alunos que demandam cada vez mais informação e rapidez na elaboração de olhares e eleição de novos interesses. A atmosfera de troca intermitente e imediata de informação que ocorre na vida dos jovens, inclusive em sala de aula, tem exigido sofisticações na composição da educação na contemporaneidade. (CINTRA; CAMURÇA; REIS, 2017, p. 409).

Neste caminhar, em consonância com pesquisa disponibilizada pelo Centro Cultural da Justiça Federal, por meio da Revista Lex Cult, do Tribunal Regional Federal da $2^{\mathrm{a}}$ Região, tem-se que na concepção de Nobre (2019):

[...] se o educador apenas age, sem refletir, incorre na falha de agir por agir, trata-se de uma ação desprovida de pensamento crítico. Por outro lado, se apenas privilegia-se a reflexão, em detrimento da ação, emite-se uma palavra oca, alienante e alienada, que não oferece transformação por quem a recebe, que não reverbera individualmente, uma vez que não admite as singularidades de cada um. (NOBRE, 2019, p. 91).

Em tal contexto, é possível interpretar o conteúdo descrito na Tabela 1, e perceber a influência da teoria pedagógica aplicada nesse ensaio. Isso acontece porque, no modelo sugerido, a mediação da aula tende em ocorrer por meio de intervenções verbais dialogadas por docente de ensino superior - na disciplina de Prática Previdenciária -, a impulsionar os alunos a chegarem em conclusões acerca do caso narrado. 
Nesse panorama, em busca realizada no banco de dados do portal do Centro Cultural da Justiça Federal, no âmbito do Tribunal Regional Federal da $2^{\text {a Região, }}$ obteve-se esse registro, concebido por Santos e Borges (2019), que afirmam que:

O papel da Mediação no empoderamento e na educação é fundamental. É por meio de uma educação reflexiva e crítica que as pessoas são empoderadas. É preciso dar voz às pessoas, despertá-las na sua capacidade de expressar, de expor ideias, de debater, discutir e de buscar condições para o seu desenvolvimento, em todos os âmbitos de sua vida.

A mediação pode promover esse tipo de educação reflexiva e crítica. (SANTOS; BORGES, 2019, p. 66).

Por isso, compreende-se a viabilidade da lição apontada, sob a luz da teorização de Vygotsky, que julga a linguagem um elemento fundamental para a assimilação, estruturação e incorporação do conhecimento.

Com o intento de reforçar a relevância da linguagem quando o assunto é processo de ensino-aprendizagem, transcreveu-se o posicionamento de Leal Júnior (2016), que expressa que:

Antes de tudo, é preciso entender e justificar porque é importante que os juízes discutam a temática relacionada à linguagem e aos textos, incorporando isso às competências que devem ser desenvolvidas, avaliadas e aperfeiçoadas no início e ao longo da carreira da magistratura.

Para compreendermos a relevância dessa temática, começamos por considerar que a jurisdição envolve a mediação e a solução de conflitos entre as pessoas. Acontece entre elas porque houve contato entre pessoas que não puderam, sozinhas, resolver determinada questão e, por isso, necessitam da mediação de um terceiro imparcial para resolver o impasse.

Para chegar à adequada solução para aquele conflito, o juiz ouvirá os argumentos de cada uma das partes (pretensão e resposta), colherá as informações necessárias para se esclarecer (prova) e, então, decidirá o caso concreto de forma racional, motivada e jurídica (sentença). Todas essas atividades envolverão linguagem e comunicação entre as pessoas (juiz, partes, advogados, testemunhas, peritos, servidores). Portanto, linguagem e texto são essenciais para o juiz, porque é por intermédio deles que o juiz consegue as informações que necessita para julgar (argumentos e provas) e comunica às partes e à sociedade o resultado desse julgamento (decisões e sentenças). (LEAL JÚNIOR, 2016, p. 90).

A partir desse ângulo, é nítida a importância da democratização da Justiça.

Por fim, dessa maneira, foram inscritas as fundamentações apropriadas que traduzem reflexos pedagógicos do estudo de caso. 


\title{
6 ANÁLISE DO ESTUDO DE CASO DO LAVRADOR DO LUGAR PAU DARCO
}

\author{
O caso aventado para o estudo refere-se à causa judicial protocolada em
} uma Vara Federal do Maranhão e trabalha conceitos técnicos do Direito, associados aos da formação humanística. Observe-se no Quadro 1 a apresentação do caso.

\section{Quadro 1 - Caso Objeto da Investigação.}

\begin{abstract}
Abordagem inicial
O Requerente tem cinquenta e sete anos de idade, baixo nível educacional, e vive em um lugar por nome Pau Darco, localizado no interior do Maranhão.

Teve indeferido seu pedido de prorrogação de auxílio-doença previdenciário em 04/02/2013, de acordo com o indeferimento em anexo, Número do Benefício (NB) 5521687641, sendo que o Autor manteve-se incapacitado para as atividades laborativas ao longo dos anos.

Ocorre que tal ato da parte requerida, em indeferir na aludida data o benefício, foi equivocado. Por se sentir injustiçado, o Demandante se socorre perante o Judiciário, para que the seja concedido o benefício a que faz "jus".

O Autor encontra-se em grave estado de saúde, possuindo documentos médicos que corroboram sua incapacidade para o labor.
\end{abstract}

\section{Documentos médicos antigos (laudos e atestado)}

Laudo Médico datado de 17/04/2013 realizado por médico vinculado ao Sistema Único de Saúde (SUS), diagnosticando ATAXIA CEREBELAR, CID 10: G 11.2.

Laudo Médico datado de 15/10/2013 realizado por médico vinculado ao Sistema Único de Saúde (SUS), diagnosticando ATAXIA CEREBELAR, CID 10: G 11.2.

Laudo Médico datado de 25/03/2014 realizado por médico vinculado ao Sistema Único de Saúde (SUS), diagnosticando ATAXIA CEREBELAR, CID 10: G 11.2.

Laudo Médico datado de 16/03/2015 realizado por médico vinculado ao Sistema Único de Saúde (SUS), diagnosticando ATAXIA CEREBELAR, CID 10: G 11.2.

Laudo Médico datado de 30/05/2016 realizado por médico vinculado ao Sistema Único de Saúde (SUS), diagnosticando ATAXIA CEREBELAR, CID 10: G 11.2.

Laudo Médico datado de 11/08/2016 realizado por médico vinculado ao Sistema Único de Saúde (SUS), diagnosticando ATAXIA CEREBELAR, CID 10: G 11.2.

Laudo Médico datado de 25/11/2016 realizado por médico vinculado ao Sistema Único de Saúde (SUS), diagnosticando ATAXIA CEREBELAR, CID 10: G 11.2.

Atestado Médico datado de 19/12/2016 realizado no Centro Integrado de Psicologia, assinado e carimbado por médico especialista (Psiquiatra) apresentando diagnóstico que aponta: paciente sem condições definitivas de exercício laborativo, CID 10: G 11.2 / G 43 / F 45.4.

\section{Exame antigo}

Laudo Tomográfico datado de 05/04/2011 realizado, por convênio SUS, no Centro de Diagnóstico e Tratamento, diagnosticando protrusão discal difusa em L4-L5, causando encoste dural.

\section{Documento médico novo}

Atestado Médico datado de 29/01/2018 realizado no Centro Integrado de Psicologia, assinado e carimbado por médico especialista (Psiquiatra) apresentando diagnóstico que aponta: paciente sem condições definitivas de exercício laborativo, CID 10: G 11.2 / G 43 / F 45.4. 


\section{Outros documentos médicos}

Encaminhamento, receituários e receituários de controle especial (documentos nas cores azul e verde).

\section{Breves ponderações}

Da análise da documentação médica juntada, percebe-se que se trata de doença que vem se prolongando há anos.

Também assim, se averigua que o Autor dispõe de um histórico de concessões de benefício de auxílio-doença previdenciário (Rural - Segurado Especial), consubstanciado ao longo dos anos. Segue descrição das aludidas cartas de concessões, ora juntadas aos presentes autos.

1. Carta de Concessão do benefício de auxílio-doença requerido em 05/07/2012 (NB 5521687641), motivando a decisão no reconhecimento da constatação de incapacidade laborativa.

2. Carta de Concessão do benefício de auxílio-doença em virtude do pedido de reconsideração de decisão, requerido em 26/04/2013 (NB 5521687641), motivando a decisão no reconhecimento da constatação de incapacidade laborativa.

3. Carta de Concessão do benefício de auxílio-doença em virtude do pedido de prorrogação de auxílio-doença, requerido em 24/09/2013 (NB 5521687641), motivando a decisão no reconhecimento da constatação de incapacidade laborativa.

4. Carta de Concessão do benefício de auxílio-doença em virtude do pedido de prorrogação de auxílio-doença, requerido em 24/03/2014 (NB 5521687641), motivando a decisão no reconhecimento da constatação de incapacidade laborativa.

5. Carta de Concessão do benefício de auxílio-doença em virtude do pedido de prorrogação de auxílio-doença, requerido em 16/03/2015 (NB 5521687641), motivando a decisão no reconhecimento da constatação de incapacidade laborativa.

6. Carta de Concessão do benefício de auxílio-doença requerido em 13/01/2017 (NB 6171693751), motivando a decisão no reconhecimento da constatação de incapacidade laborativa.

1.

\section{Algumas proposições}

Nessa senda, o Autor comprovou encontrar-se incapacitado para o seu trabalho ou para a sua atividade habitual, cumprindo as exigências contidas no art. 59 da Lei nº 8.213/91.

No que se relaciona com a qualidade de segurado especial do Requerente, assevera-se que este a detém, uma vez que anexou junto com a exordial o INFBEN (Informações do Benefício), constando neste a seguinte data da última Cessação do Benefício (DCB) de auxílio-doença previdenciário (Rural 
- Segurado Especial): 12/10/2018 (NB 6171693751). Assim, é clara a qualidade de segurado especial do postulante.

Fonte: Autor (2018).

Ao fazer a análise do caso em estudo, explicitaram-se algumas conclusões a serem ponderadas. Ei-las.

Trata-se de caso que envolve matéria constitucional, uma vez que o mérito da causa dialoga com disposições da Constituição Federal de 1988 (CF/88). Sob esse prisma, acentua-se que o artigo $6^{\circ} \mathrm{da} \mathrm{CF} / 88$ expõe que:

Art. 60. São direitos sociais a educação, a saúde, a alimentação, o trabalho, a moradia, o transporte, o lazer, a segurança, a previdência social, a proteção à maternidade e à infância, a assistência aos desamparados, na forma desta Constituição. (BRASIL, [1988]).

Outrossim, o artigo 201 da Constituição Federal de 1988 dispõe que:

Art. 201. A previdência social será organizada sob a forma de regime geral, de caráter contributivo e de filiação obrigatória, observados critérios que preservem o equilíbrio financeiro e atuarial, e atenderá, nos termos da lei, a: I - cobertura dos eventos de doença, invalidez, morte e idade avançada; [...] (BRASIL, [1988]).

Em sendo assim, convém detectar os aspectos importantes relativos à incapacidade laboral do assegurado por consistir em elemento essencial para deliberação sobre o direito ao benefício previdenciário de auxílio-doença. Isso acontece porque a parte requerida da demanda judicial reconheceu a qualidade de segurado especial do Autor, no âmbito administrativo, quando the concedeu referido benefício. Por isso, o cerne do debate centra-se na averiguação do requisito da incapacidade laboral do lavrador.

Desta feita, verificou-se pela averiguação do caso descrito no Quadro 1, que o trabalhador rural percebeu por mais de cinco anos auxílio-doença previdenciário, na via administrativa, no âmbito da Autarquia Previdenciária, parte oponente na demanda judicial. Diagnosticou-se que o trabalhador rural começou a receber auxíliodoença em 05/07/2012, na qualidade de segurado especial, bem assim que à época do protocolo da ação judicial, a data da última Cessação do Benefício (DCB) de auxílio-doença previdenciário (Rural - Segurado Especial) foi em 12/10/2018.

Com base nisso, concluiu-se que pela durabilidade/tempo que a Autarquia Federal concedeu o benefício de auxílio-doença ao lavrador, houve reconhecimento 
que a enfermidade do mesmo é significativa. Então, esse indicador foi sopesado/avaliado.

Sublinhou-se, ainda, que o trabalhador rural desse estudo de caso é pessoa de idade avançada, e de baixa escolaridade.

Pertine lembrar que "[...] o trabalho rural [...] tem sempre o desconforto típico da sua execução, quase sempre braçal [...]." (MENEZES, 2019, p. 3).

Nessa esteira, relacionou-se que as atividades realizadas por trabalhador rural exigem emprego da força, e que o crítico estado de saúde do lavrador do estudo de caso - circunstância depreendida pela vasta documentação apontada no Quadro 1 -, o impede de desenvolver as ações próprias do labor rurícola para que possa sobreviver. A documentação, de longa data, citada no relato do caso, dá conta do preenchimento do requisito da incapacidade laboral.

Observou-se que os laudos médicos apresentados pelo lavrador, foram emitidos predominantemente por médicos especialistas vinculados ao Sistema Único de Saúde (SUS) e atestam que as doenças apuradas incapacitam o paciente para o desempenho das atividades laborais definitivamente.

Nesse raciocínio, insta realçar que a dignidade da pessoa humana é um dos fundamentos da República Federativa do Brasil. (BRASIL, [1988], grifo nosso).

Em tal horizonte, note-se o estudo publicado pelo Centro Cultural da Justiça Federal, eis que Baldanza e Friede (2018) explicam que:

A educação baseada em direitos propõe que além das disciplinas básicas ministradas nos ambientes educacionais seja incluída a educação em direitos humanos como ferramenta útil ao fortalecimento de uma cultura de direitos em que prevaleçam os valores dos direitos humanos. (BALDANZA; FRIEDE, 2018, p. 62).

Nessa trilha, aduz-se o artigo 42 da Lei no 8.213/91, que discorre acerca dos Planos de Benefícios da Previdência Social. Veja-se:

Art. 42. A aposentadoria por invalidez, uma vez cumprida, quando for 0 caso, a carência exigida, será devida ao segurado que, estando ou não em gozo de auxílio-doença, for considerado incapaz e insusceptível de reabilitação para o exercício de atividade que Ihe garanta a subsistência, e ser-lhe-á paga enquanto permanecer nesta condição. (BRASIL, 1991).

Constatou-se, ao final, que o trabalhador rural do estudo congrega os requisitos ditados pela lei encimada para perceber aposentadoria por invalidez. Nesse 
ponto, reafirma-se que o segurado especial recebeu por mais de cinco anos auxíliodoença previdenciário no âmbito administrativo, é pessoa de idade avançada, baixa escolaridade e desenvolvia trabalhos relativos às atividades rurais (geralmente braçais, e que impõem a aplicação de força).

Diante das questões pontuadas e ventiladas, teve-se a resolução à pergunta de partida que impulsionou essa pesquisa, pois a análise desvendou uma metodologia adequada para ensinar acadêmicos de Direito, na disciplina de Prática Previdenciária, sobre o auxílio-doença.

\section{CONCLUSÃO}

Essa pesquisa consistiu em um ensaio que deslindou sobre demanda proposta no âmbito da Justiça Federal, referenciada na investigação como uma Justiça Cidadã por reverberar a democratização da Justiça.

Desenredou-se o estudo de caso relacionado a uma causa empreendida em uma Vara Federal do Maranhão como estratégia para ensinar, no contexto da disciplina de Prática Previdenciária, sobre o auxílio-doença. Alinhou-se ao entendimento de Vygotsky - que acredita na influência da linguagem para o desencadeamento do processo de ensino-aprendizagem. Logo, despontou, sob o prisma teórico, uma interação acadêmica e institucional, a incutir o amadurecimento do assunto: democratização da Justiça.

Apurou-se a coerência da estratégia de aprendizagem sugerida nesse trabalho, ao descortinar o exame do auxílio-doença previdenciário por meio do estudo de caso. Bem assim, fundamentou-se acerca da adequação do emprego dessa metodologia pedagógica ao mostrar que o estudo de caso é prescrito pelas diretrizes pedagógicas da Escola Nacional de Formação e Aperfeiçoamento de Magistrados e pelo Projeto Político Pedagógico da Escola da Magistratura Regional Federal da 2a Região.

Depreendeu-se que a iniciativa de investigar, nesse viés, uma ação processual atinente ao auxílio-doença previdenciário, protocolada em uma Vara Federal do Maranhão, instigou a compreensão do tema pelo aspecto científico. 
Verificou-se que o estudo de caso, na presente análise, demonstrou o ensino por meio de um problema, focalizando na autonomia cognitiva para intensificar/potencializar a independência no processo de ensino-aprendizagem. Averiguou-se que o caso apreciado dialogou a ponderação de uma experiência real pela vertente científica. Diagnosticou-se, enfim, que o exame do caso objeto da investigação aglutinou o ensino com a pesquisa.

Portanto, o estudo de caso, notadamente, constitui uma modalidade de metodologia ativa, a contribuir com o ensino do auxílio-doença previdenciário, no campo da Prática Previdenciária, sob a percepção teórica de Vygotsky.

\section{REFERÊNCIAS}

BALDANZA, Fernanda; FRIEDE, Reis. Educação em direitos humanos como instrumento de transformação social. Lex Cult Revista do CCJF, [S. I.], v. 2, n. 1, p. 51-71, 2018. Disponível em:

http://lexcultccjf.trf2.jus.br/index.php/LexCult/article/view/34. Acesso em: 28 abr. 2020.

BRASIL. [Constituição (1988)]. Constituição da República Federativa do Brasil de 1988. Brasília, DF: Presidência da República, 1988. Disponível em: http://www.planalto.gov.br/ccivil_03/constituicao/constituicao.htm. Acesso em: 12 abr. 2020.

BRASIL. 0 uso de metodologias ativas colaborativas e a formação de competências. [Brasília, DF]: Ministério da Educação, 2020. Disponível em: http://basenacionalcomum.mec.gov.br/implementacao/praticas/caderno-depraticas/aprofundamentos/202-o-uso-de-metodologias-ativas-colaborativas-e-aformacao-de-competencias-2. Acesso em: 12 abr. 2020.

BRASIL. Lei no 8.213, de 24 de julho de 1991. Dispõe sobre os Planos de Benefícios da Previdência Social e dá outras providências. Brasília, DF: Presidência da República, 1991. Disponível em:

http://www.planalto.gov.br/ccivil_03/LEIS/L8213cons.htm. Acesso em: 12 abr. 2020.

CINTRA, Carlos César Sousa; CAMURÇA, Eulália Emília Pinho; REIS, Ulisses Levy Silvério dos. O uso de novas tecnologias de informação e comunicação nas salas de aula da Faculdade de Direito da Universidade Federal do Ceará: ferramentas agregadoras ou disruptivas do processo de ensino-aprendizagem? Revista do Programa de Pós-Graduação em Direito da UFC, Ceará, v. 37, n. 2, p. 405-422, 2017. Disponível em: http://periodicos.ufc.br/nomos/article/view/31060. Acesso em: 28 mar. 2020. 
CONSELHO NACIONAL DE JUSTIÇA. Justiça em números 2019. Brasília, DF: CNJ, 2019. Disponível em: https://www.cnj.jus.br/pesquisas-judiciarias/justica-emnumeros/. Acesso em: 11 abr. 2020.

ESCOLA DA MAGISTRATURA REGIONAL FEDERAL DA 2a REGIÃO. Projeto político pedagógico. Rio de Janeiro, RJ: EMARF, 2016. Disponível em:

https://www10.trf2.jus.br/portal/emarf-portaria-institui-projeto-politico-pedagogico/. Acesso em: 28 mar. 2020.

ESCOLA NACIONAL DE FORMAÇÃO E APERFEIÇOAMENTO DE MAGISTRADOS. Diretrizes pedagógicas da ENFAM: para formação e aperfeiçoamento de magistrados. Brasília, DF: ENFAM, 2017. Disponível em:

https://bdjur.stj.jus.br/jspui/bitstream/2011/116264/Res_7_Enfam_2017_Diretrizes_ Pedagogicas_Enfam\%20_Texto_\%20Principal.pdf. Acesso em: 28 mar. 2020.

FACHIN, Odilia. Fundamentos de metodologia. São Paulo: Saraiva, 2006.

FRASSON, Antonio Carlos; OLIVEIRA JÚNIOR, Constantino Ribeiro de. Metodologia da pesquisa científica. São Luís: UemaNet, 2010.

LAKOMY, Ana Maria. Teorias cognitivas da aprendizagem. Curitiba: InterSaberes, 2014.

LAZZARI, J. B. Os juizados especiais como instrumento de acesso à justiça e de obtenção de um processo justo. Revista CEJ, Brasília, DF, ano 20, n. 70, p. 29-37, 2016. Disponível em: https://revistacej.cjf.jus.br/revcej/article/view/2164. Acesso em: 14 abr. 2020.

LEAL JÚNIOR, C. A. S. A linguagem, o texto e o juiz. Revista CEJ, Brasília, DF, ano 20, n. 68, p. 89-98, 2016. Disponível em:

https://revistacej.cjf.jus.br/revcej/article/view/2057. Acesso em: 14 abr. 2020.

MENEZES, Olindo. Notas sobre o crime de redução a condição análoga à de escravo. Revista do Tribunal Regional Federal da $1^{\text {a }}$ Região, [S. /.], v. 31, n. 3, p. 1-5, 2019. Acesso em: https://revista.trf1.jus.br/trf1/article/view/136. Acesso em: 14 abr. 2020.

NOBRE, Isabelle Rocha. Pedagogia dialógica de afeto e libertação: uma reflexão a partir da prática da professora Luana Tolentino. Lex Cult Revista do CCJF, [S. I.], v. 3, n. 3, p. 88-103, 2019. Disponível em:

http://lexcultccjf.trf2.jus.br/index.php/LexCult/article/view/207. Acesso em: 28 abr. 2020.

NOGUEIRA, Makeliny Oliveira Gomes; LEAL, Daniela. Teorias da aprendizagem: um encontro entre os pensamentos filosófico, pedagógico e psicológico. Curitiba: InterSaberes, 2015. 
PRODANOV, Cleber Cristiano; FREITAS, Ernani Cesar de. Metodologia do trabalho científico: métodos e técnicas da pesquisa e do trabalho acadêmico. Novo Hamburgo: Feevale, 2013.

SANTOS, Elaine Cler Alexandre dos; BORGES, Pedro Pereira. Educação: pré-requisito para atuação no processo de mediação. Lex Cult Revista do CCJF, [S. I.], v. 3, n. 2, p. 50-75, 2019. Disponível em:

http://lexcultccjf.trf2.jus.br/index.php/LexCult/article/view/158. Acesso em: 28 abr. 2020.

SOUSA, Ana Kennya Félix Ribeiro de; SERRA, Ilka Márcia Ribeiro de Sousa.

Metodologia da pesquisa e elaboração do trabalho de conclusão de curso.

São Luís: UemaNet, 2011. 